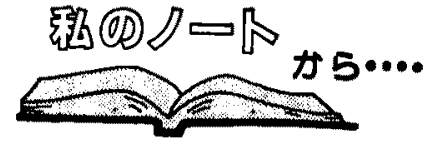

Mihalczo 法の 2 計数管化の検討
1.はじめに

未臨界度測定法の一つとして, 最近 Mihalczo 法(1) (以下M法)が有望視されている。これ恃 3 個の電流ゆ らぎ険出器の自己(APSD) 括上び相互(CPSD)パワー スペクトル密度 $G_{n m}$ を測定し，スベクトル比 $S_{R}$ を

$$
\frac{1}{S_{R}}=\frac{G_{11}(\omega) G_{23}(\omega)}{G_{12}{ }^{*}(\omega) G_{13}(\omega)}
$$

で定義すると, 検出器効窈拉よび周波数 $\omega$ 依在性が消 之， $G_{23}$ を通して $F / F_{\mathrm{c}}$ なる核分裂レート比が浅るので， その增倍率体存性を摘出してゆく巧妙な方法である。

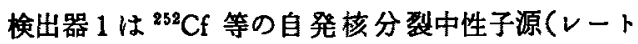
$F_{e}$ )を内葴する特殊な源核分裂㭘出電離箱で*, 検出器 2 と 3 は中性子電離箱である。中性子検出器を 2 個用 いた理由を考察するに，APSD $G_{22}$ を用いると生ずる 検出器雑音成分**がCPSD $G_{23}$ ならば避けられるので, 異時刻相関量を測り易いためであるら。

そこで検出器をバルス計数管とし，カウントを時間 領域でのみ処理すれば検出器雜音相当の妨害は生じ ボ，(1)式相当の㑚定が 2 愉出器で可能となると考え， 立式してみたところカウント法にも利点が期待できる ことを知ったので，本稿を識者に提示してみたい。

\section{2. 尌数管の谒合}

ゲート幅 $T$ 内の相関バルスベフの期待数 $c_{n m}(T)$ を おって(1) 式右辺相当量 $c_{11}(T)$ * $c_{22}(T) /\left\{c_{12}(T)\right\}^{2}$ を 作りたい所であるか，以下を考えねばならない。

計数管 1 はM法と同しく自発核分裂源を含み，分裂 片により は体系然料の自発核分裂レートF より十分強い必要 があるが、計数効率到は1.0でなくてもよいので, 源が 強すぎるならその一部のみが計数化される椣造とし，

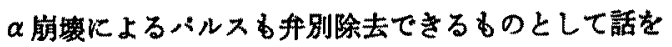
進める。（たたし，点状源近仙 $R_{\varepsilon}=1$ 守るには源 全体が小型なること。)

問題は $F_{\mathrm{c}}$ がランダムに起るので, $c_{11}=\overline{c_{1}\left(c_{1}-1\right)}-$

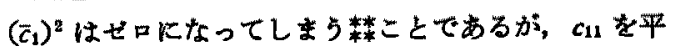

均カウント数 $\bar{c}_{1}(T)$ で固換し，同時に分母の $c_{12}$ のつ を $c_{2}(T)$ で直換して分子母で相殺関係を保つ工夫を した。

計数管 2 は中性子吸収型とし, 自己相関べフ期待数 (X2)を, $c_{22}=\overline{c_{2}\left(c_{2}-1\right)}-\left(\bar{c}_{2}\right)^{2}$ にっって計数する。牫 る $c_{12}$ は，計数管 1 が計数した源核分裂と同族の中性子 が計数管 2 以計数される相互相関べアの期待数で，a12 $=\overline{C_{1} c_{2}}-\left(\bar{c}_{1}\right)\left(\bar{c}_{2}\right)$ で与えられる。問題は同時ゲートでの 計数 $c_{1}, c_{2}$ を 2 次元スターシに詝めて行がばならぬ ことであるか，可能な技術であろらと考えられる。

以上炕より，2計数管のみの計数統計により

$$
\begin{aligned}
& \frac{1}{C_{z}}=\frac{\bar{c}_{1}(T) c_{22}(T)}{\bar{c}_{2}(T) c_{12}(T)} \\
& =\frac{\bar{c}_{1}\left\{\overline{c_{2}\left(c_{2}-1\right)}-\left(\bar{c}_{2}\right)^{2}\right\}}{\bar{c}_{2}\left\{\bar{c}_{1} c_{2}-\bar{c}_{1} \bar{c}_{2}\right\}}
\end{aligned}
$$

を作ることで(1)式の $1 / S_{R}$ に類似の量が得られ，增

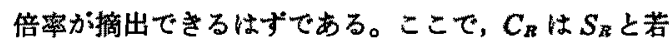
干異なるので記号を变えたが，以下に立式して示す。

\section{3. 竍数管ての測定是の立式}

計数管 1 は源核分裂レート $F_{\mathrm{c}}$ を效摔 $\varepsilon_{1}$ で計数し，

$$
\bar{c}_{1}(T)=\varepsilon_{1} F_{\mathrm{c}} T
$$

計数管 1,2 相関バルスペフは, 基本モード点状源近

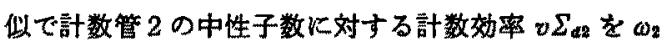
と記して, 即発中性子チェインのみを相関対象とし,

$$
\begin{aligned}
c_{12}(T) & =\varepsilon_{1} F_{c} \omega_{2} \bar{\nu}_{c p} \bar{I}_{c} \int_{0}^{T} d t_{1} \int_{t_{1}}^{T} e^{-\alpha\left(t-1 t^{2}\right)} d t_{2} \\
& =\frac{\varepsilon_{1} F_{c} \omega_{2} \bar{\nu}_{e p} \bar{I}_{e}}{\alpha} T\left(1-\frac{1-e^{-\alpha T}}{\alpha T}\right)
\end{aligned}
$$

ここで, $\bar{I}_{e}:$ 源中性子の平均インボータンス

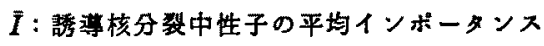
$\bar{c}_{2}(T)$ では遅発中性子まで計算に入れねばならず,

$$
\begin{aligned}
& \bar{c}_{z}(T)=\omega_{2}\left(\frac{\bar{\nu}_{c p} \bar{I}_{e} F_{\mathrm{c}}}{1-\beta_{\varepsilon}}+\frac{\bar{\nu}_{p} \bar{I} F_{\alpha}}{1-\beta}\right) \\
& \cdot\left[\left\{\int_{-\infty}^{T} d t_{1} \int_{0}^{x} d t_{2}+\int_{0}^{T} d t_{1} \int_{t_{1}}^{T} d t_{2}\right\} e^{-d t u+-t+1}\right] \\
& =\frac{\omega_{\varepsilon} \bar{\nu}_{c p} \bar{I}_{c} F_{c}}{\alpha} \cdot \frac{1-\beta}{1-\beta_{e}} \cdot \frac{T}{\left(1-\frac{\beta}{1-k_{p}}\right)}
\end{aligned}
$$

*この特殊性が，何らかの䋓対值測定また恃選発 臨界での校正なしに，增倍率測定を可能にして いるボイントである。

**捈出器 2 の模出レートC 2 に比例した振㷧で全の 領域に入る白色蓶音。

**スベース節的のため, 記号仕おおむね文献(2)に よるすのとし, 再捛しない。

橉梚出器雑音化相当するるのが時間領城では入ら すとすむことの基返し。 
ただし，F、は遅発中性子が起寸核分裂レートで，誘 尊核分裂レート $F$ ，源核分裂レート $F_{\mathrm{c}}$ と次の関㐿があ る。

$$
F_{d}=\beta F=\beta \frac{k_{\text {erf }}}{1-k_{\text {eft }}} \cdot \frac{1-\beta}{1-\beta_{c}} \cdot \frac{\bar{\nu}_{c p} \bar{I}_{c}}{\bar{\nu}_{p} \bar{I}} F_{c}
$$

最後に， $c_{22}(T)$ は即発中性子相関べアのみを数卡

$$
\begin{aligned}
& c_{22}(T)=2\left[F_{\varepsilon} \omega_{2}^{2} \overline{I_{e} \cdot I_{c}} \cdot \overline{\nu_{c p}\left(\nu_{c p}-1\right)}\right. \\
& \left.+F \omega_{2}^{2} \overline{I \cdot I} \cdot \overline{\nu_{p}\left(\nu_{p}-1\right)}\right] \\
& \cdot\left[\left\{\int_{-\infty}^{0} d t_{1} \int_{0}^{T} d t_{2} \int_{t_{3}}^{T} d t_{3}\right.\right. \\
& \left.\left.+\int_{0}^{T} d t_{1} \int_{t_{1}}^{T} d t_{2} \int_{t_{3}}^{T} d t_{3}\right\} e^{-\alpha\left(t_{3}+t_{2}-2 t_{1}\right)}\right] \\
& =\frac{\omega_{2}^{2}}{\alpha^{2}}\left[F_{c} \overline{I_{\varepsilon} \cdot I_{\varepsilon}} \cdot \overline{\nu_{q p}\left(\nu_{c p}-1\right)}\right. \\
& \left.+F \overline{I \cdot I} \cdot \overline{\nu_{p}\left(\nu_{p}-1\right)}\right] T\left(1-\frac{1-e^{-\alpha T}}{\alpha T}\right)
\end{aligned}
$$

である。以上から(2)式を作ると $T$ 依存性は相殺され

$$
\begin{aligned}
\frac{1}{C_{R}}= & \frac{1-\beta_{c}}{1-\beta}\left(1-\frac{\beta}{1-k_{p}}\right)\left(\frac{\bar{\nu}_{c p}\left(\nu_{c p}-1\right)}{\left(\bar{\nu}_{c p}\right)^{2}} \cdot \frac{\overline{I_{c} \cdot I_{c}}}{\left(\bar{I}_{c}\right)^{2}}\right. \\
& \left.+\frac{\overline{\nu_{p}\left(\nu_{p}-1\right)}}{\left(\bar{\nu}_{p}\right)^{2}} \cdot \frac{\bar{I} \cdot I}{(\bar{I})^{2}}\left(\frac{\bar{\nu}_{p} \bar{I}}{\bar{\nu}_{c p} \bar{I}_{s}}\right)^{2} \frac{F}{F_{c}}\right](8)
\end{aligned}
$$

ここで，M法にならっで(2) (9)式を用いると，(10)式 を得る゙。

$$
\begin{aligned}
\frac{\overline{\mathcal{D}}_{p} \bar{I} F}{\overline{\mathcal{D}}_{c p} \bar{I}_{c} F_{c}}= & \frac{1-\beta}{1-\beta_{c}} \cdot \frac{k_{\mathrm{orr}}}{1-k_{\mathrm{ort}}} \\
= & \frac{1-\beta}{1-\beta_{c}} \cdot \frac{1}{\left(1-\frac{\beta}{1-k_{p}}\right)} \cdot \frac{k_{p}}{1-k_{p}} \\
\frac{1}{C_{R}}= & \frac{1-\beta_{c}}{1-\beta}\left(1-\frac{\beta}{1-k_{p}}\right) X_{\mathrm{c}} R_{c} \\
& +\frac{k_{\phi}}{1-k_{p}}\left(\frac{\bar{\nu}_{\rho} \bar{I}}{\overline{\mathcal{L}}_{\mathrm{c} p} \bar{I}_{\mathrm{c}}}\right) X R
\end{aligned}
$$

この結果はM法に打ける1 $/ S_{R}$ に比して， $\alpha$ 崩壊の影

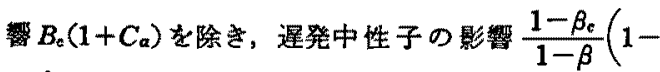
$\left.\frac{\beta}{1-k_{p}}\right)$ 倍を入れたるのになっているが，本質的な内 容は変わっていない**。ただし，M法と違って反応度 $|\rho|$ Kついて解く型とせす，「上記 (10) 式を数値的に 満たす $k_{p}$ をっててこの体系の即発中性子增倍率之す る。よいら型の測定法と考えるのが自然である。

\section{4. 新数管法の利点}

上記の計数管による方法はM法に比して

(1) 検出器が 2 個でする，その分，空間体存補正 が楽。

（2）非增倍系での $1 / S_{\text {Rout }}$ の測定に当るるのが不
要策。

（3）ゲート幅 $T$ 传存性が分子母で相殺するが，T を变えて確認しつつ進及得て，そ礼上るる平均 $C_{R}$ はM法の $S_{R}$ の周波数 $\omega$ Kよる裂動より落ち 着くであろら。

(4) カゥント数処理の方が電流法に上り装固的に 多分楽。

などが挙げられるが，さらに重要なことは

(5) 中性子增倍率だけでなく，測定量を5まく組 み合わせることによって，体系の炬物理量が分 解して求的られるという特長加あり，以下に之 の式を示しておく。

\section{5. 体系の炉物理的諸量の導出}

反応度 $|\rho| ：(10)$ 式で求められた $k_{\rho}$ を用いて

$$
|\rho|=\frac{1-\beta}{k_{p}}-1
$$

即発中性子减哀定数 $\alpha: c_{12}(T)$ または $c_{22}(T) の T$ 依存性を追い，(4)，(7)式にフィットして求め $3 * * 0$

即発中性子平均寿命 $\tau_{0}$ ：動特性では $l$ とも書く量 で

$$
\tau_{0}=\frac{1-k_{p}}{\alpha}
$$

核分裂飞対寸る平均寿命 $\tau_{f} ： 1 / v \Sigma_{f}$ 亿相当する量 で

$$
\tau_{s}=\frac{\bar{\nu}_{p} \bar{I}}{k_{p}} \tau_{0}
$$

源核分裂レート $F_{c}$ ：不感時間計数ロスがないとし $\tau$

$$
\left.\frac{c_{12}(T)}{\bar{c}_{1}(T) \bar{c}_{2}(T)}\right|_{r \rightarrow 0}=\frac{1-\beta_{c}}{1-\beta}\left(1-\frac{\beta}{1-k_{p}}\right) \frac{\alpha}{2 F_{0}}
$$

上り， $k_{p}$ と $\alpha$ の導出後化 $F_{\mathrm{c}}$ 方決定される。

誘導核分裂レートF：（8）式に上るか，末たは定 義式で

$$
F=\frac{1-\beta}{1-\beta_{c}} \cdot \frac{k_{p}}{1-\beta-k_{p}}\left(\frac{\bar{\nu}_{c p} \tilde{I}_{c}}{\bar{\nu}_{p} \bar{I}}\right) F_{c}
$$

計数管 1 の計数勃率 $\varepsilon_{1}$ ：源核分列 1 個当り

* $R_{t}=\frac{\overline{I_{c} \cdot I_{c}}}{\left(\bar{I}_{c}\right)^{2}}, R=\frac{\overline{I \cdot I}}{(\bar{I})^{2}}$. なお， インボータンス $I_{c}$, $I は \alpha$ 隇衰モードの劯起振楅比例量として定義。

** $1 / C_{R}$ は $1 / S_{R}$ と遑って遅発臨界で $\rightarrow \infty$ とならない が、これは一長一短である。なお，すしす死で荤 発中性子の影響を除去できれ估, $1 / S_{R}$ と同型にな るところである。

**あえてこれを行えば Diven因子 $X_{6} の\left(1-\beta_{\mathrm{c}}\right)$ 倍索 実測する型になる。

粦Feynman- $\alpha$ 法類似である。 


$$
\varepsilon_{1}=\frac{\bar{c}_{1}(T)}{F_{\mathrm{c}} T}
$$

計数管 2 の計数効祭: 源核分裂 1 個当りの即発同 族中性子計数奻㛙 $\varepsilon_{2}$ は, $T \rightarrow$ 大での飽和值に上り

$$
\left.\frac{c_{12}(T)}{\bar{c}_{1}(T)}\right|_{T \rightarrow 大}=\frac{\omega_{2} \bar{\nu}_{c p} \bar{I}_{c}}{\alpha} \equiv \varepsilon_{2}
$$

で，誘導核分裂 1 個当りの遅発中性子を含む計数 は

$$
\begin{aligned}
\bar{\varepsilon}_{2}^{\prime} & =\frac{\bar{c}_{2}(T)}{F T}=\frac{\omega_{2} \bar{\nu}_{p} \bar{I}}{\alpha} \cdot \frac{1-k_{p}}{k_{p}} \\
& =\frac{\omega_{2} \bar{\nu}_{p} \bar{I}}{k_{p}} \tau_{0}=\omega_{2} \tau_{f}
\end{aligned}
$$

である。これから $\varepsilon_{2}^{\prime}$ あ心 あ出せる。

6.おわりに

以上により，2 個の計数管を用いて 3 検出器のM法

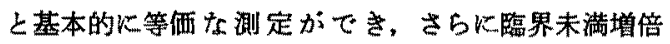
系の师物理的諸量が分解して求められることが知られ た。しかし，精度を士げようとすれは，高次もードを どら取り扱らか(3)とか，(6)，(9)式中のインポータ
ンスが(8)式中のそれと全く同じでよいのか上か, 詳 細な検討が今後む必要であるし，何よりる(10)式中の

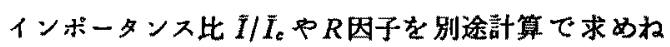
ばならないのはM法と変わらない。今啳これらの值を 実験的に求める方法はないかなど考えると面白いが， 今回はとりあえず，計数管による相関実験の再興に期 待して，立式できた所までを記した次第である。

$$
\text { (1988年 12月12日 受理) }
$$

\section{一专考文献一}

(1) Mhaalczo, J.T., Paré, V.K.: Ann. Nucl, Energy, 2, 97 (1975).

（2）山根義宏，代科浩三郎，他：原子力誌，28[9]，850(1986). (本稿の記号·表式で説明のないるのはこの文献を参照 $\left.D=\varepsilon_{0}\right)$

（3）仁科浩二郎：昭62年度科研費補助金(一般研究 B ) 研究成

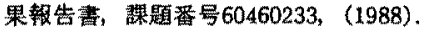
なお，本稿はベージ数が十分とれないので，同一内容 で若干丁䕗に記しためのとして次を作ってある。

（4）古橋晃：動然事業団技街資料 PNC N 1410 88-001 (1988).
IAEA/ANL.Int. Workshop on Safety of Nuclear Installations of the Next Generation and Beyond

1989年8 月28 31 日 (Chicago, Illinois, USA) Subject-areas

(1) Safety objectives for future large-scale deployment of nuclear power

(2) Safety aspects of the next generation of current-type nuclear power plants

(3) Safety aspects of new designs and concepts for nuclear plants, including the nuclear fuel cycle

Deadline for submission of three copies of abstracts $(1,000$ words or less): June 19, 1989.

Author notification July 17, 1989.

Two copies of the abstracts should be sent to Jan B. van Erp, Argonne National Laboratory, Argonne, IL 60439, USA; Phone 312-972-3381; Fax 312-972-3193.

One copy should be sent to Ahmad Karbassioun, IAEA, P.O. Box 100, A-1400 Vienna, Austria; Phone 43-1-23602686; Fax 43-1-234564.

パネルディスカッションのパネリストとして，三島良辕氏 (果大名管)，知元基(果大)の両氏が出席の予定。国内の Technical Programme 委冒は三島良紿氐です。

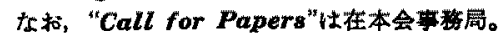

（社）日本工学会主催

\section{第 4 回国際会境のための準備セミナー}

英語によるプレゼンテーションの実際

会期 1989年5月16日(火), 17日(水)

会地 末 定

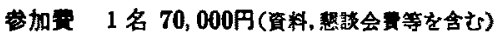

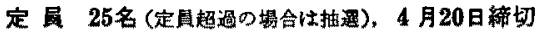

参加申込方法 Nガキに氏名·年龄·勤筑先名·所属·役㬝名·住

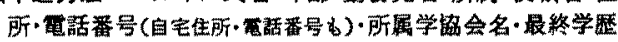
•参加貫青求先を記入して下記へ。

(なお，詳細プログラムは下記宛倩求して下さい)

申 込先（テ107)東京都港区赤坂9-6-41 乃坂ビル

（社）日本工学会 (03-475-4621)

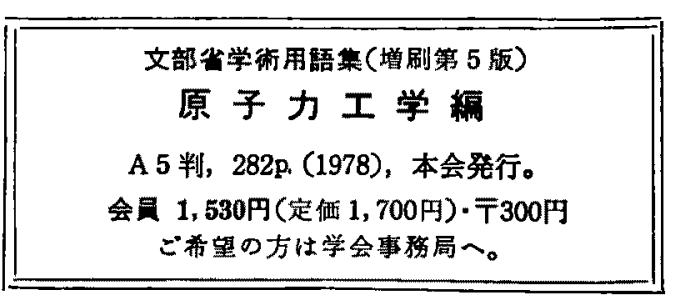

